\title{
Prémio Ferreira da Silva 2012 e Medalha Vicente de Seabra 2012
}

O Prémio Ferreira da Silva foi instituído pela Sociedade Portuguesa de Química em 1981, sendo atribuído com carácter bienal a um químico português que, pela obra científica produzida em Portugal, tenha contribuído significativamente para o avanço da Química, em qualquer das suas áreas. Já a Medalha Vicente Seabra, instituída mais recentemente pela SPQ, nomeadamente em 2002, tendo sido atribuída pela 1. ${ }^{a}$ vez em 2004 durante o XIX Encontro Nacional da SPQ, destina-se a premiar a alta qualidade, originalidade e autonomia do trabalho de investigação em Química desenvolvido em Portugal por um investigador de idade não superior a 40 anos.

O júri do Prémio Ferreira da Silva 2012 e da Medalha Vicente de Seabra 2012 reuniu na sede da SPQ, no dia 10 de dezembro de 2012, decidindo a atribuição, por unanimidade, do Prémio Ferreira da Silva 2012, ex-aequo, a Armando José Latourette de Oliveira Pombeiro, Professor Catedrático do Instituto Superior Técnico (UTL) e a José Luís Fontes da Costa Lima, Professor Catedrático da Faculdade de
Farmácia da Universidade do Porto. Decidiu ainda atribuir a Medalha Vicente de Seabra 2012 a Pedro Miguel Pimenta Góis, Investigador Auxiliar da Faculdade de Farmácia da Universidade de Lisboa. Os premiados proferirão conferências no próximo Encontro Nacional da SPQ, a realizar em Aveiro entre 12 e 14 de junho deste ano.

\author{
Joana Amaral \\ (bquimica@ipb.pt) \\ www.spq.pt
}

\section{SPQ Apoia Reunião Sobre o Ensino da Química no Secundário e Partilla Preocupações dos Departamentos e dos Professores}

Por iniciativa do Departamento de Química da Faculdade de Ciências da Universidade do Porto, e com o apoio da SPQ, realizou-se no dia 9 de janeiro, no Porto, uma reunião de departamentos de Química, Engenharia Química e áreas afins, com a presença de representantes da FCUP, FEUP, UTAD, UM, UBI, UA, UC, IP de Tomar, ISEL, IST, FCUL e UAlg.

A necessidade desta reunião foi despoletada pela forma como o Ministério da Educação tem vindo a tratar o ensino da química. A centralidade da química como ciência de base e a sua importância para a formação científica e técnica dos nossos jovens é de tal modo evidente que não se justifica qualquer tipo de argumentação comparativa relativamente às demais ciências. Seria como justificar a necessidade de nos alimentarmos para nos desenvolvermos saudavelmente.

Olhando para a situação que se vive é possível identificar vários sinais preocupantes, que deixam todos os responsáveis pelo ensino da química apreensivos. O sistema actual de acesso ao ensino superior, as condições frágeis de natureza laboratorial, a (curta) carga horária e a organização curricular não ajudam o ensino experimental, incontornável na ciência química.
Além do corte de carga lectiva nesta importante disciplina, acresce alguma dispersão para a adaptação necessária nas escolas. Esta situação demonstra falta de sensibilidade à formação científica em geral e ao desenvolvimento da educação química, em particular. A tendência para a sistematização desmesurada da avaliação face ao ensino conduziu a um desenquadramento entre a extensão dos programas, a duração dos períodos lectivos e a colocação dos momentos de avaliação.

Os programas curriculares de química precisam de ser reformulados, nomeadamente recentrando-os em conceitos estruturantes (mais do que em contextos) e removendo alguma dispersão, alguns vazios e alguma amplitude (em muitos casos a extensão demasiada prejudica a qualidade das abordagens). É evidente a desconexão e a falta de continuidade no secundário, sobretudo na passagem do $11 .^{\circ}$ para o $12 .^{\circ}$ ano.

Identificados alguns dos problemas, tornou-se óbvia a necessidade de um debate alargado no seio das instituições com responsabilidade no ensino desta disciplina. A presente reunião foi a forma encontrada para dar início a um processo construtivo de resolução das questões identificadas. Iniciou-se com uma interessante apresentação de José Ferreira Gomes sobre alguns aspectos da situação internacional e nacional da química e do seu ensino. Seguiram-se várias intervenções e trocas de pontos de vista sobre a colocação dos exames no currículo, a estrutura e redução dos programas, o ensino experimental, as restrições sobre a constituição de turmas de $12 .^{\circ}$ ano, o acesso ao ensino superior, entre outros pontos.

Da reunião resultou um documento que será apresentado ao Ministro da Educação e que assentará num conjunto de recomendações básicas ao nível da formação experimental dos estudantes, da organização curricular, sobretudo ao nível do $12 .^{\circ}$ ano, onde a posição da química está demasiado fragilizada face à atual estrutura de avaliação e, finalmente, a revisão curricular dos programas específicos de química, sobretudo ao nível do secundário, no que respeita à extensão e conteúdo. $O$ documento encontra-se em fase de revisão para ser apresentado ao gabinete do Ministro da Educação, após a qual será disponibilizado no portal da SPQ.

\footnotetext{
Direção da SPQ

(sede@spq.pt)

www.spq.pt
} 